\title{
$e_{\text {-TEALS }}^{\text {no. } \mid 2016}$
}

\section{Assessing Speaking Proficiency: A Challenge for the Portuguese EFL Teacher}

An e-journal of Teacher Education and Applied Language Studies

\begin{abstract}
Speaking has been increasingly promoted in curricula, both nationally and internationally, as one of the major aims of foreign language teaching. However, the unique features of this skill make it the most challenging one to assess. Portuguese EFL teachers seem to be at odds with suitable assessment procedures designed to monitor students' progress. This paper examines the rationale underlying some of the core concepts on educational classroom-based assessment, including their definitions and key characteristics, as well as briefly outlining the theoretical premises of the communicative competence model designed by Canale and Swain to suggest what may be assessed. It also focuses on a new approach to language assessment - learning-oriented assessment, by highlighting its twofold potential to be the link between instruction and what is learned and to promote effective student learning. The paper concludes with two different practical examples of how to assess speaking in the classroom with a learning-oriented perspective in mind.
\end{abstract}

Key words | English as a Foreign Language, speaking, speaking proficiency, assessment, learning, learning-oriented assessment

Citation: Rúben Constantino Correia,"Assessing Speaking Proficiency: A Challenge for the Portuguese EFL Teacher."e-TEALS: An e-journal of Teacher Education and Applied Language Studies 7 (2016): 87-108. ISSN $1647-712 X$

DOI: 10.1515/eteals-2016-0009 


\section{e-TEALS no. 7 (2016): 87-107}

Assessing Speaking Proficiency | Rúben Constantino Correia

\section{Introduction}

The search for more effective ways of teaching English as a Foreign Language (EFL) gave rise to different teaching methods/approaches on both sides of the Atlantic over the past century. From those, the Communicative Language Teaching (CLT) approach emerged as the one adopted by most practitioners, marking "a major paradigm shift within language teaching in the twentieth century, one whose ramifications continue to be felt today" (Rodgers and Richards 151). CLT argues for genuine communicative exchanges through activities designed to develop the students' ability to use language appropriately and meaningfully. Naturally, the importance of oral skills in language syllabuses and curricula grew and led to increasing research in this area, with the focus largely on the need to measure ability and the best way to do it. ${ }^{1}$ Hence, considerable attention has been drawn both to assessment and the context in which it operates. However, assessment has become a popular but "sometimes misunderstood term in current educational practice" (Brown 4) and for this reason a distinction between the terms assessment and testing, which are repeatedly used interchangeably, must be made. Given its broaden nature, evaluation is consciously not addressed in this paper. It "refers to a process of systematically collecting information in order to make a judgement. Evaluation can thus concern a whole range of issues in and beyond language education: lessons, courses, programs, and skills can all be evaluated" (Cameron 222).

Testing is an administrative product-oriented procedure, usually imposed by the teacher that occurs at specific moments with the purpose of measuring second/foreign language knowledge for scoring and grading. Tests are often a norm-referenced instrument - scores are compared amongst students, used to determine individual ability or demonstrate mastery of a given skill, and offer limited information to identify areas for improvement because they tend to be "one-off" events of speaking proficiency. When a teacher gives a test, he/she is obtaining a narrow sample of the test-taker's performance in a specific domain that doesn't account for the progress made (or not) based on that performance. On the other hand, assessment is an 


\section{e-TEALS no. 7 (2016): 87-107}

Assessing Speaking Proficiency | Rúben Constantino Correia

ongoing process-oriented approach that takes many different forms. One of these forms are tests. Thus, testing is a subset of assessment and should be seen as one of the many methods available to assess students' verbal performance. Assessment is often a criterion-referenced measurement - students' performance being compared against a set of criteria, used in educational contexts to monitor students' strengths and weaknesses. It is operated in a systematic way for the purpose of helping "teachers find out what students are learning in the classroom and how well they are learning it" (Angelo and Cross 4). Assessments serve as tools to draw inferences that the teachers can rely on about the students' achievements, and to make the necessary adjustments in the teaching-learning environment, i.e. using assessment results to change practices which in turn assist students to improve their speaking proficiency. In a nutshell, "assessment is the systematic collection, review, and use of information . . . undertaken for the purpose of improving student learning and development" (Banta and Palomba 4), entailing careful planning, implementing and acting upon the results. Assessment goes beyond the question how much the students have learned; instead, it asks how they learned and what can be done to improve their learning.

\section{The Nature of Speaking}

Speaking is an interactive process performed in real-time with particular patterns and structures influenced by the participants involved, their purposes, the topic, the setting in which it takes place, and so forth. The speaker must master and mobilize an array of linguistic knowledge vocabulary, sound system (segmental features), suprasegmental aspects like stress, intonation and rhythm and language functions - along with the kinesics and semiotics usually related to spoken language to avoid extensive hesitation or communicational breakdowns.

Speaking may be broadly characterised by the use of incomplete sentences, connected or not with conjunctions, what Luoma (12) conceives of as idea units, short turns between interlocutors, together with simple interrogative structures, manipulation of strategies for creating time to speak, such as fillers, hesitation markers and repetitions, and informal features (e.g., 


\section{e-TEALS no. 7 (2016): 87-107}

Assessing Speaking Proficiency | Rúben Constantino Correia

simpler syntax). Everyday L2 classroom speaking interactions - a pupil asking permission to go to the toilet or the teacher giving instructions, involve message-oriented interaction (conveying information), the main point is to make the message clear to the listener and confirm if he/she has understood it accurately.

\section{Defining the Problem}

Speaking has unique traits that make it the most distinctive and probably the most difficult skill to assess. Unlike writing, speaking is done spontaneously greatly restricting the possibility to plan one's discourse before processing and producing it. Thus, the teacher/assessor has to judge, in real-time, production and/or interaction related to several aspects of what is being said (range, accuracy, fluency, interaction, coherence). ${ }^{2}$ Furthermore, in Portugal the assessment of speaking proficiency faces a major challenge - the reluctance of Portuguese state school teachers to address it. Most students studying English at the lower levels ( $5^{\text {th }}$ up to $9^{\text {th }}$ graders) are overloaded with grammar instruction and exercises, usually done via course-books, quizzes or worksheets. Clearly, the emphasis given to linguistic competence outweighs that given to linguistic performance, which in turn hinders the students' speaking proficiency and the assessment process itself. Although this paper does not report on empirical research, my claim is grounded in my teaching experience in ten different schools for the past fourteen years, both in Lisbon and the Algarve.

\section{What and How to Assess}

The context in which EFL is delivered in Portuguese classrooms is broadly homogenous - the teachers are non-native speakers; the students share and speak the same first language and English is not used continuously outside the classroom. Yet, learners and teachers themselves differ in their reactions to the learning process. As regards the first group, some lack motivation whilst others welcome the opportunity to further develop their speaking ability. As for the second group, some perceive the assessment of speaking proficiency as a lofty goal whereas others 


\section{e-TEALS no. 7 (2016): 87-107}

Assessing Speaking Proficiency | Rúben Constantino Correia

organize diversified speaking assessments that are stimulating. Thus, while it is (perhaps) utopian to think of a clear-cut formula for assessing speaking proficiency in any given class, some suggestions can be put forward. Each teacher develops his/her speaking assessment specifications with a particular set of students in mind.

Every practitioner should have a clear idea of what and how to assess in the classroom. With regard to the former, bearing in mind the objective of increasing speaking proficiency, it is appropriate to consider the influential model of Communicative Competence designed by Canale and Swain. For the authors, Communicative Competence is "the relationship and interaction between grammatical competence, or knowledge of the rules of grammar, and sociolinguistic competence, or knowledge of the rules of language use" (Canale and Swain 6). Later, the model was further developed by other scholars, like Savignon (8), to include a strategic and a discourse competence. This means that the teacher may decide what to assess for speaking proficiency by considering four areas of accuracy: grammatical competence - grammar rules, vocabulary and pronunciation; sociolinguistic competence - appropriateness of language use (vocabulary, register, style and politeness) in different contexts with different people; strategic competence - strategies used by the speaker/learner to compensate breakdowns or enhance communication (kinesics and circumlocution); and discourse competence - the ability to manage turn-taking and connect utterances to form a meaningful reasoning.

Naturally, the question of how to assess these competences arises. The answer is a difficult one; even amongst researchers the best way to assess students' speaking proficiency lacks consensus. I strongly advocate a holistic approach to assessment, i.e. using more than one method for assessing speaking proficiency. The collection of a variety of speech samples over time will allow the teacher to have an overall understanding about the students' linguistic performance - what he/she is or is not able to produce, yet. Classroom speaking assessments can take many forms, ranging from more simple/discrete ones like pattern drills to practise contextualised minimal pairs (for instance minimal pairs bingo), to more complex/integrative ones like social-interactive tasks (debates, role-plays and/or interviews) to practice a blend of 
e-TEALS no. (2016): 87-107

Assessing Speaking Proficiency | Rúben Constantino Correia

the aforementioned areas of accuracy. In-between there are other tasks to measure the students' speaking proficiency. Some of the possibilities are:

- $\quad$ Pair and/ or group tasks (e.g., doing an information gap exercise);

- Description/ Comparison tasks (e.g., the student is given one or two different objects to describe and/or compare);

- Opinion-expressing tasks (e.g., presenting a meaningful up-to-date topic to the students, for instance technology, and elicit their opinion);

- $\quad$ Storytelling tasks (e.g., students tell stories from their childhood using visual input - Little Red Riding Hood);

- $\quad$ Game-based tasks (e.g., playing a guessing game).

Considering the twofold context of the classroom - the need for a systematic assessment of the learners' progress and frequency of spontaneous oral interactions amongst students - another measurement of speaking proficiency may be observation. By observation I do not mean the perceptions teachers have of students' aptitude from every question, answer, attitude, etc., occurring day in and day out. To establish observation as a valid and reliable classroom assessment technique requires record keeping, from simple anecdotal notes to score rubrics, criteria sheets, checklists, or even a mixture of all four. The key point is making sure that assessment should reflect instruction and be meaningful for the learners.

According to Cohen, "typical classroom interactions involve teacher utterances and shorter learner responses" (279), which means that, regardless of the selected assessment method, Portuguese EFL teachers must rethink questionable practices and promote a paradigm shift in their classrooms. Effective speaking assessments hinge on extensive chunks of spoken language and on full responses from the learners, otherwise the process of assessing speaking proficiency in itself may come to a halt. 


\section{e -TEALS no. 7 (2016): 87-107}

Assessing Speaking Proficiency | Rúben Constantino Correia

\section{Aligning Assessment with Learning}

Used wisely, assessment can be the most substantial stimulant for learning. However, to do so, a paradigm shift must take place. If we truly want to integrate assessment with instruction, we need to reconceptualise several well-established beliefs. As shown above, our concerns have to move from testing to learning, and therefore to the individual; and grading outcomes ought to become subsidiary to learning outcomes.

From the beginning of the $21^{\text {st }}$ century onwards, a new framework has steadily gained ground in the field of educational assessment, the learning-oriented assessment approach. This innovative view of pedagogy "holds that for all assessments, whether predominantly summative or formative in function, a key aim is for them to promote productive student learning" (Carless, "Learning-Oriented Assessment: Principles, Practice and a Project"). Hence, whatever form the assessment takes it must be a means of supporting learning and, simultaneously, to acknowledge its centrality. Implementing a learning-oriented assessment approach to speaking "involves the collection and interpretation of evidence about performance so that judgments can be made about further language development" (Purpura 236) to promote knowledge. Analysing Purpura's words carefully, we conclude that evidence is the core ingredient of learning-oriented assessments. After being collected from multiple sources, evidence helps teachers to monitor students' progress, shows students' acquisition (or otherwise) of what is being taught, and provides meaningful feedback for students and teachers alike. Ideally, this broader range of information should generate a constant reanalysis from both parties. Thus, students are able to identify their weaknesses and set objectives that will lead to improvement and teachers have the opportunity to reflect upon the work developed and restructure all the necessary language instruction procedures to meet students' learning needs.

For those who may think learning-oriented assessment is complicated, Carless summarizes it in three simple principles. Bearing these principles in mind, teachers will be able to engage learners in productive assessment activities. 
Principle 1: Assessment tasks should be designed to stimulate productive learning practices amongst students;

Principle 2: Assessment should involve students actively in engaging with criteria, quality, their own and/or peers' performance [sic];

Principle 3: Feedback should be timely and forward-looking so as to support current and future student learning. ("Learning-Oriented Assessment: Principles, Practice and a Project" 83).

Learning-oriented assessment elements are also set forth by Carless ("Learning-Oriented Assessment: Conceptual Bases and Practical Implications" 60) in schematic form:
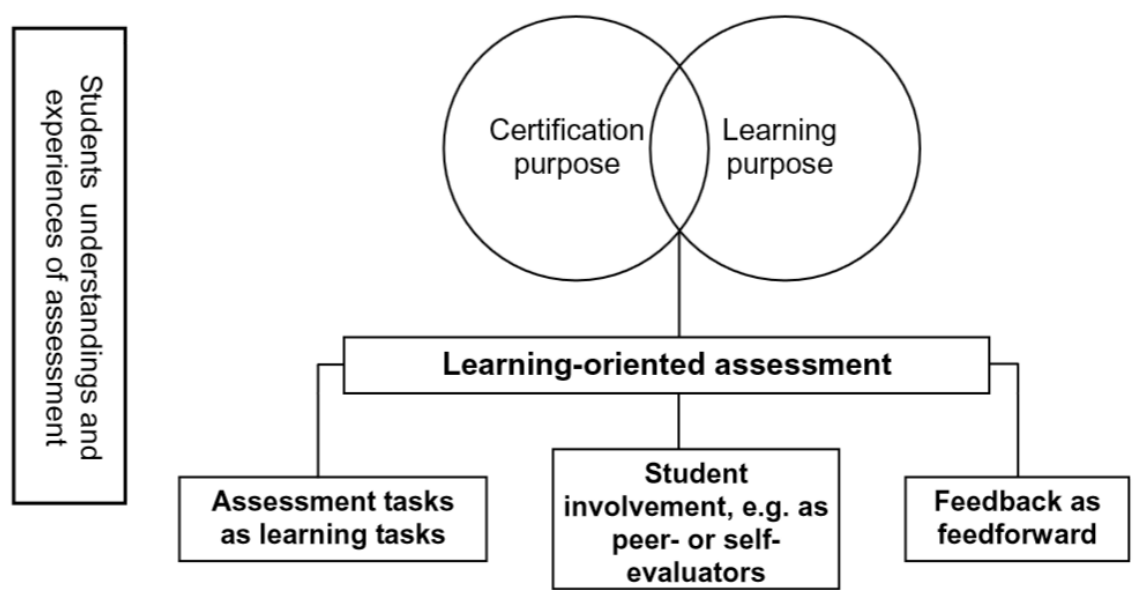
evaluators

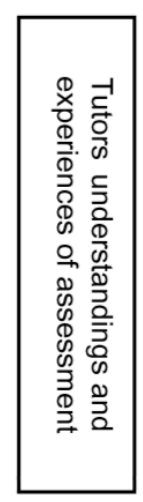

Figure 1 - Framework for Learning-Oriented Assessment

Such a framework aligns curriculum, learning and assessment with the main stakeholders. It must be interpreted as a whole and not just as a sum of the parts, a well-oiled machine whose cogs work in unison towards the same outcome - successful learning. At the centre, we have the purposes of assessment, which are envisioned as overlapping. Learning and certification interconnect with each other enhancing the learning features of assessment. To achieve their intended purposes, appropriate tasks should be designed, students have to be involved and feedback has to be significant. First, learning tasks should be conceptualised as assessment tasks and vice-versa, encompassing the anticipated learning goals by promoting interactional authenticity, a reflection of the real-world and collaborative work. Second, students must be given the opportunity to understand the criteria and standards applied to their work, 


\section{e-TEALS no. 7 (2016): 87-107}

Assessing Speaking Proficiency | Rúben Constantino Correia

enabling them to accurately judge whether they meet these criteria and standards or not. "The conceptual rationale for peer assessment and peer feedback is that it enables students to take an active role in the management of their own learning" (Liu and Carless 280). Third, feedback must be timely, relevant and able to be acted upon by the students, i.e. functions as feedforward. If it does not help students close the gap between their expected learning outcomes and the present state, it doesn't really qualify as feedback. This should make us wonder if it is actually feedback we have been providing our students with.

Learning-oriented approaches to speaking should not be concerned only with measuring ability, but also with actual learning of pronunciation (segmental and suprasegmental aspects), vocabulary, language functions, register, turn-taking and breakdowns compensation. Thus, teachers must make sure that learning/assessment tasks represent spontaneous, real-life spoken interaction and target the speaking aspects the students are supposed to use. As a teacher guided by a learning-oriented assessment approach, I want to grasp what my students know, understand and can use with relation to every speaking subset, and employ the data collected to develop their ability, and meet individual needs. Common learning/assessment measurements related to speaking, which can take place at any phase of the learning process, include, as discussed in section 4, dialogues, interviews, role-plays, descriptions (photographs or images), giving instructions, story-telling, opinion-expressing/justifying and discussions (done through pair or group work). At times, when students are struggling with specific subsets of speaking, contextualised discrete learning/assessment activities are also valuable. Bring dictionaries to class to help with stressed syllables, play "Pronunciation Bingo" to practice vowel contrasts in words with similar pronunciation patterns, ask students to read aloud to enhance intonation and rhythm, and so forth. There is a plethora of choices. ${ }^{3}$ Implementing a learning-oriented assessment approach to speaking proficiency means designing interesting and cognitively appealing tasks, which simultaneously foster enjoyment for learning. Besides "task design and operationalization, teachers also need to consider how assessment relates to and can help promote [speaking] acquisition" (Purpura 236). 
Considering the rationale presented in this section, I believe that one of the major issues concerning speaking assessment in the current Portuguese EFL classroom is the lack of assessment literacy. By assessment literacy I mean not only having the knowledge of what assessment is and means, including its terminology; but also, having the knowledge of assessment methodologies and techniques, how to assess, how to analyse and interpret the results from the assessments, and how to apply this data to improve students' learning. Even those who are open-minded enough to embrace a change in practice do not feel comfortable going beyond what they experienced as learners themselves and now perpetuate as teachers. It is possible to implement new speaking assessment procedures in Portugal grounded in a learning-oriented approach, but for now the step forward requires a change of mentality/attitude and a significant increase in assessment literacy.

\section{Practicalities}

When the teacher sets out to assess the students' speaking proficiency he or she initiates a speaking assessment cycle (Figure 2), which Luoma uses to show the different stages of the process (5).

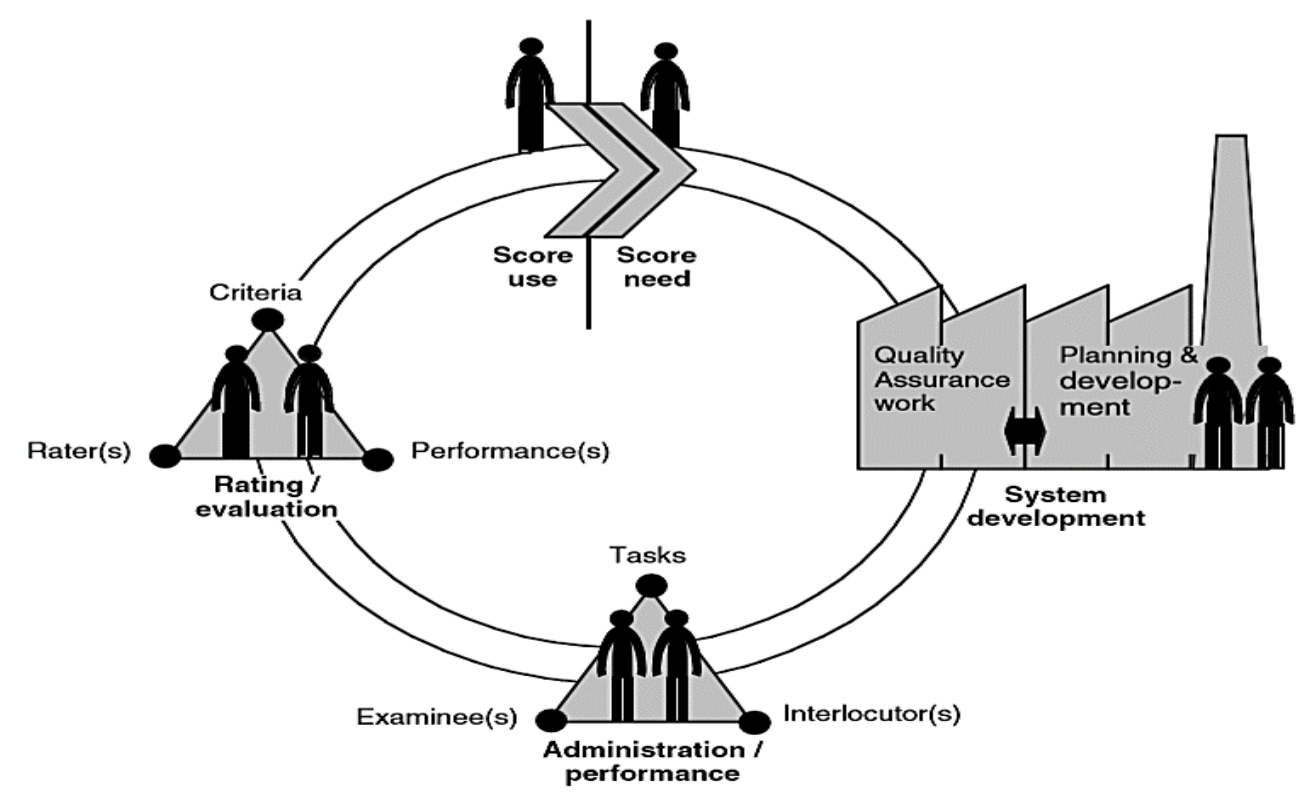

Figure 2 - Speaking Assessment Cycle 


\section{e-TEALS no. 7 (2016): 87-107}

Assessing Speaking Proficiency| Rúben Constantino Correia

One of the examples introduced by Luoma to test speaking involves the following scenario:

There are two examinees and two testers in the testing room. Both examinees have four pictures in front of them, and they are constructing a story together. At the end of their story, one of the testers asks them a few questions and then closes the discussion off . . . After the examinees leave, the testers quickly mark their assessments on a form

Although important as a basis for working, the cycle must be looked at with caution. Luoma conceives it with a norm-referenced testing perspective in mind; therefore, for a classroom environment, it requires some adaptations. There are three key differences to take into account:

$1^{\text {st }}$ - the assessment developer, the interlocutor, the rater ${ }^{4}$ and the assessment user is the teacher;

$2^{\text {nd }}-$ the assessment method quite often is not a test;

$3^{\text {rd }}$ - accordingly, there are no examinees but only students. Moreover, I also drop the terms score need/use and replace them with assessment need/use.

The constant need to assess students sets in motion the speaking assessment cycle. To address the challenge, the teacher has to think about the purpose of the assessment (learning-oriented assessment) that will guide the speaking assessment cycle thereafter. With a clear purpose in mind, the teacher moves on to step two, planning and developing quality assessment tasks and criteria that meet the anticipated learning goals. If needed, instructions are also planned and developed at this stage. Moving to stage three, the students do the assessment tasks given by the teacher, who may or may not interact with the students depending on the tasks chosen. Closely connected to stage three, at stage four the teacher assesses the students' performance against the set of criteria developed earlier. Lastly, to close the assessment cycle, the assessment results should be used by the teacher to check if the 
students have achieved or not the learning goals intended for them. As argued in section 4, this last step implies timely feedback that can be acted upon by the students, especially for those whose performances show greater weaknesses.

The two examples which follow provide a practical illustration of what and how to assess speaking proficiency, based on the suggestions made in section 4, as applied to the Speaking Assessment Cycle.

\section{Example 1}

Assessment Need and Purpose: Considering the difficulty of Portuguese students in pronouncing the phonemes $/ ð /$ and $/ \theta /$, there is a need to understand whether the students can differentiate them or not. The purpose here is twofold - to help promote students' phonic awareness about the consonant digraph \{th\} and to help students struggling with pronunciation.

Planning and Developing: Bearing in mind that the students are $5^{\text {th }}$ graders, the task of choice should involve a known context, in this case family relationships, and have some kind of guidance. Accordingly, the students, working in pairs, ask and answer questions about the relationship of the family members in the family tree given. To follow the teacher's objective, instead of relationship terms such as mother, father, etc. (which have been taught previously), personal names are used.

Assessment Task: This is when the teacher's planning and development comes into play. The students are introduced to the task they have to carry out and start their interaction (see the task used in Appendix 1 below).

Performance Assessment: Without disturbing, commenting and interrupting the students' performance flow, the teacher assesses each pair according to the criteria planned and 
developed at step two. Bearing in mind the European setting, the criteria are comprised of short descriptors of speaking proficiency, following the CEFR rationale:

\begin{tabular}{|c|l|}
\hline Level & \multicolumn{1}{|c|}{ Pronunciation Descriptors } \\
\hline 5 & Pronounces both phonemes accurately; \\
\hline 4 & Rarely mispronounces; \\
\hline 3 & $\begin{array}{l}\text { Substitutes } / \mathrm{t} /, / \mathrm{s} /, / \mathrm{f} / \text { for voiceless } / \theta / \text { or } \\
/ \mathrm{d} /, / \mathrm{z} /, / \mathrm{v} / \text { for voiced /ठ/; }\end{array}$ \\
\hline 2 & $\begin{array}{l}\text { Substitutes } / \mathrm{t} /, / \mathrm{s} /, / \mathrm{f} / \text { for voiceless } / \theta / \\
\text { and } / \mathrm{d} /, / \mathrm{z} /, / \mathrm{v} / \text { for } \text { voiced } / \mathrm{d} / ;\end{array}$ \\
\hline 1 & Is unintelligible. \\
\hline
\end{tabular}

Depending on the students/class assessed, another criteria item can be added:

\begin{tabular}{|c|c|c|}
\hline Level & Pronunciation Descriptors & Speech Flow Descriptors \\
\hline 5 & Pronounces both phonemes accurately; & Speaks fluently; \\
\hline 4 & Rarely mispronounces; & Rarely hesitates; \\
\hline 3 & $\begin{array}{l}\text { Substitutes /t/, /s/, /f/ for voiceless } / \theta / \\
\text { or /d/, /z/, /v/ for voiced /ð/; }\end{array}$ & $\begin{array}{l}\text { Maintains flow of speech but uses } \\
\text { repetition and/or self-correction; }\end{array}$ \\
\hline 2 & $\begin{array}{l}\text { Substitutes } / \mathrm{t} /, / \mathrm{s} /, / \mathrm{f} / \text { for voiceless } / \theta / \\
\text { and } / \mathrm{d} /, / \mathrm{z} /, / \mathrm{v} / \text { for voiced } / \delta / \text {; }\end{array}$ & $\begin{array}{l}\text { Hesitations are frequent and disrupt } \\
\text { the flow of speech; }\end{array}$ \\
\hline 1 & Is unintelligible. & $\begin{array}{l}\text { Speech flow so halting that little } \\
\text { interaction is possible. }\end{array}$ \\
\hline
\end{tabular}

Assessment use: The cycle is completed with a careful analysis of the assessment results. The teacher uses them to understand if the students' performances meet the expected learning goals, as well as the assessment purpose. Within a reasonable period of time, the teacher tells the 
students how well they did. The use of positive feedback is advisable, especially for those whose performances show a bigger gap between their expected learning outcomes and their present state. The teacher devises extra activities for this particular group in order to help overcome the students' difficulties. There are a few possibilities, but I usually give students two lists of specific words to be practised at home and, later, pronounced in class. Usually, I let these students repeat the Assessment Task.

\section{Lists of words}

/ð/

$\begin{array}{ll}\text { Father } & \text { mother } \\ \text { this } & \text { that } \\ \text { other } & \text { together }\end{array}$

weather

\begin{tabular}{llll} 
& & \multicolumn{1}{c}{$/$} & \\
brother & Matthew & Keith & Cynthia \\
there & thanks & month & teeth \\
Netherlands & thirteen & nothing & mouth \\
& truth & &
\end{tabular}

\section{Example 2}

Assessment Need and Purpose: With a class of Portuguese $9^{\text {th }}$ graders in mind (B1 threshold level learners), who are expanding their English communicative skills, there is a need to simulate possible real-life situations that include different speech acts. The purpose here is to probe for the ability to combine some or all aspects of grammatical competence, sociolinguistic competence, strategic competence and discourse competence together.

Planning and Developing: Such an assessment purpose demands the use of some sort of social-interactive task. Considering the classroom context in which the task will take place and the speaking level of the learners, my choice is a role-play. Instead of a teacher-learner role-play, I opt for role-plays between learners. From my teaching experience, as well as in literature (O'Sullivan), there is evidence that learner acquaintanceship improves performance. I would say it also improves motivation and avoids the effect of inhibition, and greater levels of spontaneity 
and fun are usually achieved. To strengthen the task's relevance, it is important to think of a scenario to which the students can easily relate. For the Portuguese setting, particularly the south of the country, the hotel receptionist + tourist scenario is appropriate. Accordingly, the students, working in pairs, are asked to take on a particular role and imagine themselves in that particular situation. Depending on the class assessed, the role-play may be more or less guided following the instructions given to the students. When planning, and developing a role-play, the teacher has to make sure that the students are familiar with role-playing, the procedure and the purpose it entails. These have to be clearly explained beforehand.

Assessment Task: This is when the teacher's planning and developing comes into play. The students are introduced to the task they have to accomplish, according to the instructions, and start their performance. If the students assessed are highly proficient the instructions are less guided and presented in general terms:

Imagine you are a foreign tourist visiting the south of Portugal (Albufeira or Portimão). You are talking to the hotel receptionist. Find out which places are worth seeing and how to get there. You may also be interested in local restaurants.

On the other hand, if the students assessed are less proficient the instructions are more guided and presented in detail:

Imagine you are a foreign tourist visiting the south of Portugal (Albufeira or Portimão). You are talking to the hotel receptionist. Explain the situation and ask for his/her help. You would like to know which places the receptionist recommends you to see. Ask for his opinion. Also, ask about transportation, travelling time, prices and good local restaurants to eat. Finally, tell the receptionist what you have decided to visit and how you will get there. 


\section{e-TEALS no.7 (2016): 87-107}

Assessing Speaking Proficiency | Rúben Constantino Correia

Performance Assessment: Without disturbing, commenting and interrupting the students' performance flow, the teacher assesses each pair according to the criteria planned and developed at step two. Bearing in mind the European setting, the criteria are comprised of short descriptors of speaking proficiency, following the CEFR rationale (see the example of an assessment grid in Appendix 2 below).

Assessment Use: The cycle is completed with a careful analysis of the assessment results. The teacher uses them to understand if the students' performances meet the expected learning goals, as well as the assessment purpose. Within a reasonable period of time, the teacher tells the students how well they did. The use of positive feedback is advisable, especially for those whose performances show a bigger gap between their expected learning outcomes and their present state. Unlike discrete tasks (example 1), which may be improved with autonomous guided practice, social-interactive tasks require a different approach. Students will not improve per se if told to repeat the task all over again, they will face the same difficulties. So, the key word here is coaching. I pair up the students with the poorer performances and sit down next to them to coach them every step of the way whenever necessary. The goal is to help the students understand how to manage turn-taking, the ability to circumlocute (afterwards, the student is told the word he did not know), and the most troublesome grammar and pronunciation errors. After this support work and peer reflection, I let these students repeat the Assessment Task.

The two examples put forward are nothing but a narrow sample of what can be done to tackle the challenge of assessing students' speaking proficiency throughout the school year, based on both the speaking assessment cycle suggested and a learning-oriented assessment approach. The rationale here is tied to section 5's explanation of the first strand of Carless's framework, where learning tasks become assessment tasks. Thus, students do not feel threatened by assessment given its similarity to the work developed in class on a daily basis. These tasks are meant to fit comfortably with the students' learning experience, matching "the teaching and learning goals of the particular class and students being assessed" (Davison and Leung 395). 


\section{Concluding Thoughts}

Assessing speaking is a difficult, time-consuming and complex task, yet necessary because speaking is the core of teaching-learning interaction. The dominance of summative assessment should diminish within schools and a more comprehensive methodology should be adopted. What matters is recognising the foremost purpose of assessment - to support learning, by constituting a bridge to close the gap between teaching and learning.

Both teachers and learners in Portugal must overcome their fears and frailties regarding spoken language assessment, and embrace a new model committed to promoting learning in a more effective manner. I reiterate the added value of the learning-oriented approach to assessment as a way to reinforce the link between learning, teaching and assessment. Such an approach allows teachers to gather evidence of students' progress towards the anticipated learning outcomes, allows teachers to use the information collected to meet individual needs and provide timely feedback, encourages students to act upon their strengths and weaknesses, supports students to have an active role in their own, as well as their peers', learning, and perhaps even more important it fosters further speaking proficiency development.

Most of all "teachers need to reflect on their assessment practices and beliefs and determine how they can use assessment practices and results to improve student language learning" (Stoynoff 531).

\section{Notes}

\footnotetext{
${ }^{1}$ Associated with the rise of CLT is the early work on "testing" by Arthur Hughes (Testing for Language Teachers) and Cyril Weir (Understanding and Developing Language Tests). Both authors shed light on the principles of testing, the qualities that every test must have and how all the four skills can be tested by providing practical guidance to help EFL teachers design better tests. Yet, although recognizing the added value of Hughes and Weir's work, I would say that from a classroom perspective tests alone may fall short of accurately capturing the learners' (spoken) ability.

${ }^{2}$ These are the qualitative aspects of spoken language use described in the Common European Framework of Reference (Council of Europe 29).

${ }^{3}$ For further examples see Wong's Teaching Pronunciation: Focus on English Rhythm and Intonation and Celce-Murcia's Teaching Pronunciation: A Reference for Teachers of English to Speakers of Other Languages.

${ }^{4}$ Sometimes the interlocutor and/or rater may also be a student, depending on the task at hand - dialogues/interviews and peer assessment.
} 


\section{Works Cited}

Angelo,Thomas, and Patricia Cross. Classroom Assessment Techniques: A Handbook for College Teachers. San Francisco: Jossey-Bass Publishers, 1993.

Banta, Trudy, and Catherine Palomba. Assessment Essentials: Planning, Implementing, and Improving Assessment in Higher Education. San Francisco: Jossey-Bass Publishers, 1999.

Brown, H. Douglas. Language Assessment Principles and Practices. New York: Longman, 2004.

Cameron, Lynne. Teaching Languages to Young Learners. Cambridge: Cambridge UP, 2001.

Canale, Michael, and Merrill Swain. "Theoretical Bases of Communicative Approaches to Second Language Teaching and Testing." Applied Linguistics (1980): 1-47.

Carless, David. "Learning-Oriented Assessment: Conceptual Bases and Practical Implications." Innovations in Education and Teaching International 44.1 (2007): 57-66.

---. "Learning-Oriented Assessment: Principles, Practice and a Project." Tertiary Assessment \& Higher Education Student Outcomes: Policy, Practice \& Research. Eds. Meyer, Luanna et al. Wellington, New Zealand: Ako Aotearoa, 2009. 79-90.

Celce-Murcia, Marianne, Donna Brinton and Janet Goodwin. Teaching Pronunciation: A Reference for Teachers of English to Speakers of Other Languages. Cambridge: Cambridge UP, 1996.

Cohen, Andrew. Assessing Language Ability in the Classroom. 2nd ed. Boston: Heinle \& Heinle, 1994.

Council of Europe. Common European Framework of Reference for Languages: Learning, Teaching, Assessment. Cambridge: Cambridge UP, 2001.

Davison, Chris, and Constant Leung. "Current Issues in English Language Teacher-Based Assessment." TESOL Quarterly 43.3 (2009): 393-415.

Hughes, Arthur. Testing for Language Teachers. 2nd ed. Cambridge: Cambridge UP, 2003.

Liu, Ngar-Fun, and David Carless. "Peer Feedback: the Learning Element of Peer Assessment." Teaching in Higher Education 11.3 (2006): 279-90. 
e-TEALS no. (2016): 87-107

Assessing Speaking Proficiency | Rúben Constantino Correia

Luoma, Sari. Assessing Speaking. Cambridge: Cambridge UP, 2004.

O'Sullivan, Barry. "Learner Acquaintanceship and Oral Proficiency Test Pair-task Performance." Language Testing 19.3 (2002): 277-95.

Purpura, James. Assessing Grammar. Cambridge: Cambridge UP, 2004.

Rodgers, Theodore, and Jack Richards. Approaches and Methods in Language Teaching. Cambridge: Cambridge University Press, 2001.

Savignon, Sandra. Interpreting Communicative Language Teaching. London: Yale UP, 2002.

Stoynoff, Stephen. "Looking Backward and Forward at Classroom-Based Language Assessment." ELT Journal 66.4 (2012): 523-32.

Weir, Cyril. Understanding and Developing Language Tests. Hemel Hempstead: Prentice Hall, 1993.

Wong, Rita. Teaching Pronunciation: Focus on English Rhythm and Intonation. New Jersey: Prentice-Hall, 1987. 
e-TEALS no. (2016): 87-107

Assessing Speaking Proficiency| Rúben Constantino Correia

\section{Appendix 1 - Assessment Task}

\section{Tree $^{1}$}

\section{/ð/ vs. $/ \theta$}

Directions: Working in pairs, ask about the relationship of the people in the family tree.

Example: Student A: Who is Keith's mother?

Student B: Keith's mother is Agatha.

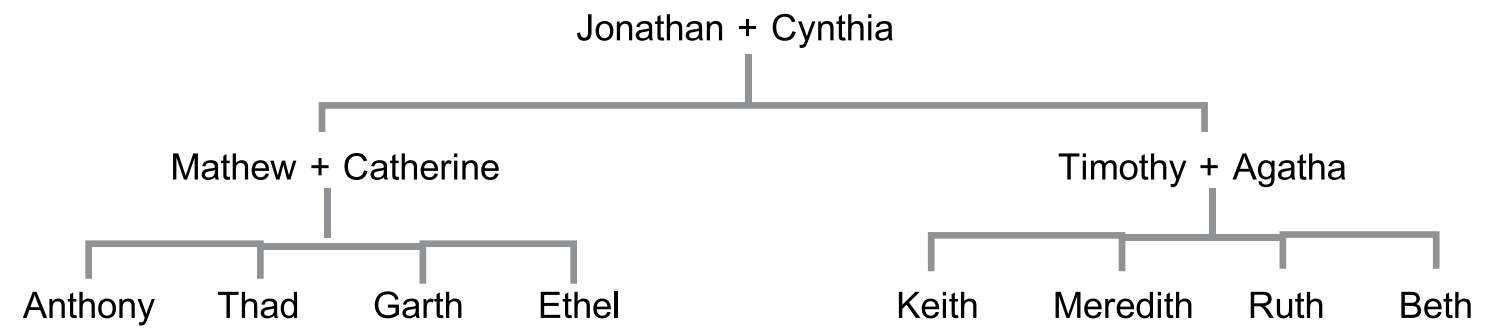

\footnotetext{
${ }^{1}$ From Teaching Pronunciation: A Reference for Teachers of English to Speakers of Other Languages (Celce-Murcia, Brinton and Goodwin 58).
} 


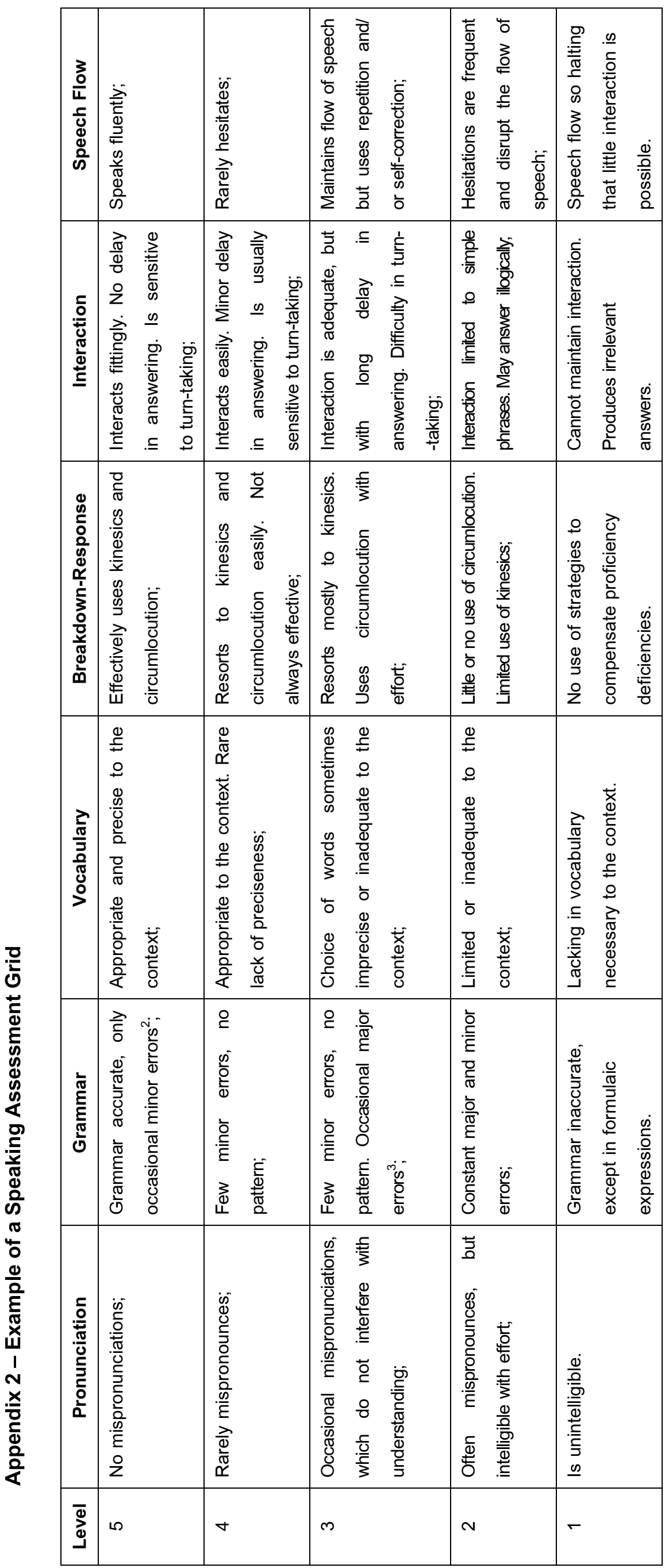

